\title{
Article \\ Implementation of AHP Methodology for the Evaluation and Selection Process of a Reverse Engineering Scanning System
}

\author{
Juraj Beniak *, L'ubomír Šooš, Peter Križan (D) and Miloš Matúš $\mathbb{D}$ \\ Faculty of Mechanical Engineering, Slovak University of Technology in Bratislava, Nam. Slobody 17, \\ 81231 Bratislava, Slovakia; lubomir.soos@stuba.sk (L'.Š.); peter.krizan@stuba.sk (P.K.); \\ milos.matus@stuba.sk (M.M.) \\ * Correspondence: juraj.beniak@stuba.sk
}

Citation: Beniak, J.; Šooš, L'.; Križan, P.; Matúš, M. Implementation of AHP Methodology for the Evaluation and Selection Process of a Reverse Engineering Scanning System. Appl. Sci. 2021, 11, 12050. https://doi.org/ 10.3390/app112412050

Academic Editors: Marek Milosz and Jacek Kęsik

Received: 14 November 2021 Accepted: 14 December 2021 Published: 17 December 2021

Publisher's Note: MDPI stays neutral with regard to jurisdictional claims in published maps and institutional affiliations.

Copyright: (c) 2021 by the authors. Licensee MDPI, Basel, Switzerland. This article is an open access article distributed under the terms and conditions of the Creative Commons Attribution (CC BY) license (https:// creativecommons.org/licenses/by/ $4.0 /)$.

\begin{abstract}
Generally speaking, the proper selection of a suitable system for various uses is key to its full use in practice. In all areas, there is a large number of technologies, equipment, and systems to choose from, so it is necessary to determine the individual parameters and their weight, which are important for selection. In the field of reverse engineering, several technological devices are particularly expensive, and the selection of one will influence the long-term functioning of the system. Reverse engineering systems are widely used for the registration and documentation of historical objects in the sense of cultural heritage, and the presented scanning systems are suitable for this purpose. In this case, the selection of a scanning system is discussed. This paper deals with the methodology of selecting the most suitable reverse engineering system by the method of pairwise comparison of expert evaluation criteria (analytical hierarchical process (AHP)). This paper contains a comparison of several systems and the selection of the most suitable solution for the particular company.
\end{abstract}

Keywords: reverse engineering; evaluation process; 3D scanners

\section{Introduction}

The aim of the research was to design a non-contact method for obtaining a digital 3D model of a produced part, so as to measure the quality of production. This is an operation that has only been carried out using contact devices so far. These excel in their greater accuracy, but their measuring speed and ability to measure free-form products are low or insufficient [1,2]. For this purpose, it was proposed to use optical systems for scanning, and then to compare the data obtained from actual manufactured products with those data from 3D digital models that were used for production $[3,4]$.

Another area of application of reverse engineering systems, such as scanning systems, is the documentation of historical objects and monuments that are part of the cultural heritage of human society [5].

As such, optical systems have come a long way during their development, and their accuracy, in which they have been lagging behind, is beginning to approach that of a coordinate measuring instrument [6-8]. The scope of their use is wide, mainly for operations with a large variety of products. Optical systems can shorten the time of measurement, as well as the evaluation of measured data, which significantly streamlines the work of the employees of the relevant department. A convincing argument for the implementation of scanning devices is also the cost saving, simplification and acceleration of the quality control process. Above all, there is an overall increase in the level of quality [9-11].

The development of technologies in reverse engineering opens new horizons in the areas of quality assurance and control. Great progress is being made with non-contact devices, the accuracy of which is beginning to approach that of conventional contact coordinate measuring instruments. One of their main advantages is the scanning speed; the systems can scan the measured object several times faster, which ultimately means 
increased productivity and the ability to control a larger number of products. Another advantage of contactless scanners is the easier and faster processing, when comparing the measured data with a CAD model, which, again, brings an increase in the productivity of quality personnel, scope to reduce labor costs, and extends quality control functions to larger production volumes [12-14]. The basic concept of the reverse engineering process is shown in Figure 1.

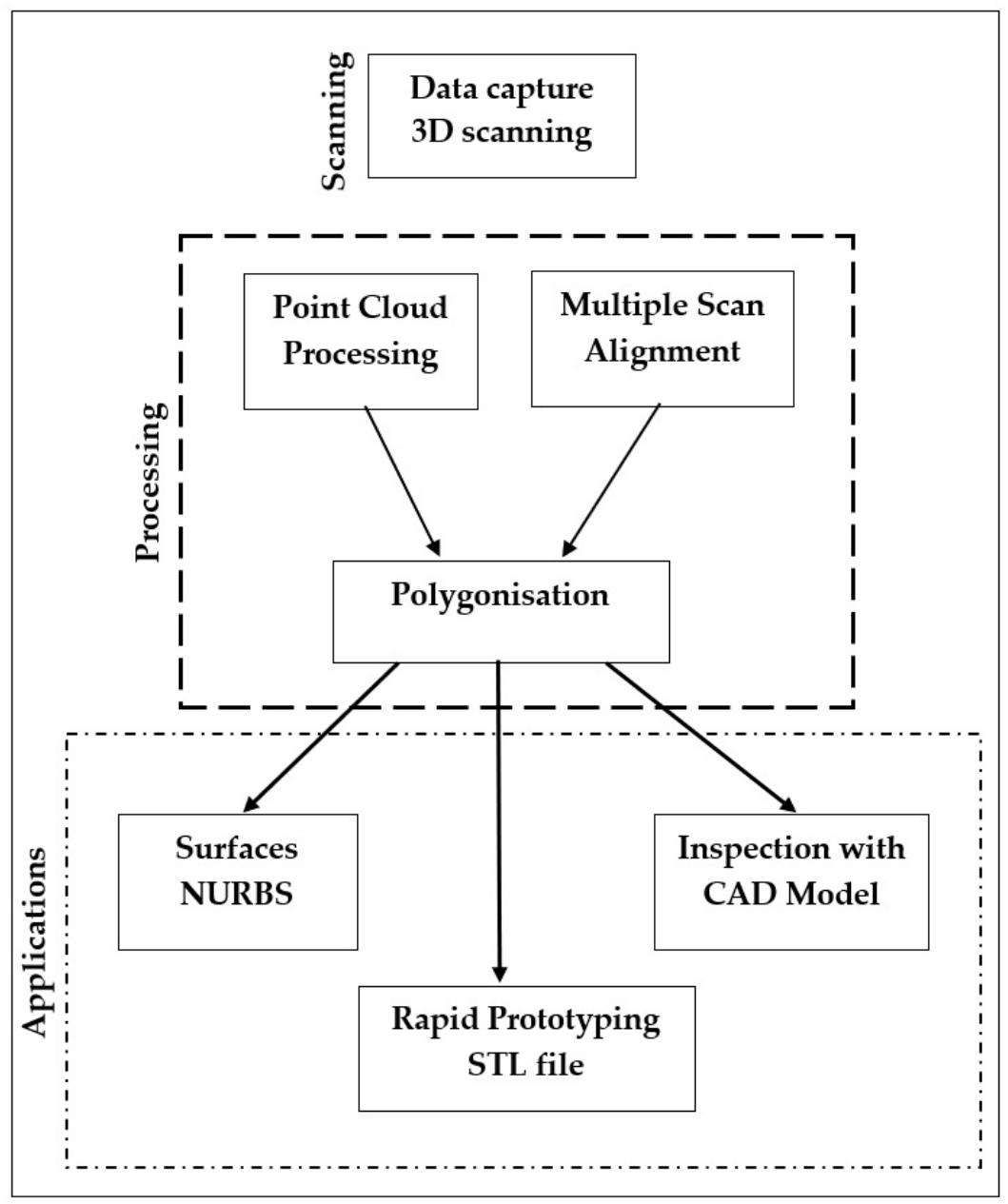

Figure 1. Reverse engineering process-basic concept.

The procurement of such technology for scanning real objects is demanding, in terms of finances and the number of alternatives available on the market. Any decision of one expert is only subjective, and may not take into account all the aspects necessary for a proper evaluation of the characteristics of the available equipment and the selection of the most appropriate solution [15]. Therefore, it is appropriate to use scientific methods to assess the selected factors, preferably with the help of experts from several fields, who have a different perspective on evaluation [16].

This article deals with the system of selecting a suitable scanning device for reverse engineering using the pairwise comparison method and AHP. Pairwise comparison is a scientific method of analyzing a number of different objects or subjects to determine if they are significantly different from one another.

There are several different methods, which are based on the same principle-assessing several variants of solving a given problem according to the selected criteria, and determining the order of these variants. The individual methods differ according to how the so-called weight of the individual criteria and the degree to which the individual variants of the solution meet the selected criteria are numerically evaluated $[17,18]$. 
DMM (decision matrix method) is considered to be a basic method (it can have several solution variants) [19-21]. One of the variants consists of evaluating the weight (importance) of individual criteria with a point scale from 1 to 10 , so that level 1 is assigned to the smallest weight and level 10 to the largest weight. The same scale also evaluates how individual variants of the solution meet the selected criteria, i.e., grade " 1 "— does not match up, to " 10 "-matches perfectly.

FDMM (modified decision matrix method) partially eliminates the disadvantages of DMM. The weights of individual criteria, as well as the evaluation of the ability of the variants to meet individual criteria, are determined by so-called pairwise comparison [22-24]. This means that when comparing the two criteria, the more important (more important for decision making) criterion is rated " 1 ", and the less important criterion is " 0 ". Similarly, when evaluating how two variants meet the selected evaluation criteria, the more satisfactory variant is rated " 1 ", and the variant rated worse is " 0 ".

AHP (analytic hierarchy process) eliminates the shortcomings of DMM and FDMM to some extent. It is also based on a pairwise comparison of the degree of significance of the individual criteria and the degree to which the evaluated solution variants meet these criteria. However, the rating scale is much more complex $[25,26]$. The evaluation is based, in both cases (comparison of criteria and variants), on so-called "expert estimation", in which experts in the field compare the mutual influences of two factors. These are evaluated on the basis of the scale equal — weak — medium — strong - very strong, while the values (1-3-5-7-9) correspond to this verbal evaluation.

\section{Materials and Methods}

For the correct selection of a suitable hardware solution for reverse engineering scanning, it is necessary to perform a thorough analysis on the basis of which the selection will be made. From the available products, a group of devices was selected for this purpose, which will be subjected to comparison. These are the following devices:

- $\quad$ MetraSCAN $70\left(a_{1}\right)$;

- MetraSCAN 70-R $\left(a_{2}\right)$;

- HandyPROBE $\left(a_{3}\right)$;

- Nikon XC65Dx $\left(a_{4}\right)$;

- Nikon LC60Dx $\left(a_{5}\right)$;

- Nikon LC15Dx $\left(a_{6}\right)$;

- Metronor DUO $\left(a_{7}\right)$;

- $\quad$ ATOS Triple Scan $\left(a_{8}\right)$.

The MetraSCAN 70, MetraSCAN 70-R, and HandyPROBE (Figure 2) are manufactured by Creaform, a Canadian company. The MetraSCAN 70 and 70-R are almost identical optical scanners. The main difference is in the compatibility of the $\mathrm{R}$ version with the mechanical arm, but only with the KR5 Arc product line from KUKA. In this configuration, the measuring system is not affected by the accuracy of the arm. The second difference is their weight; the lighter version of MetraSCAN 70 is designed for manual handling, so it is characterized by high portability. A necessary part of both scanners is the C-Track 380 position evaluation system and the VXelements software (data collection), which can be connected to the Metrolog X4 i-Robot software with more sophisticated measurement evaluation tools. 


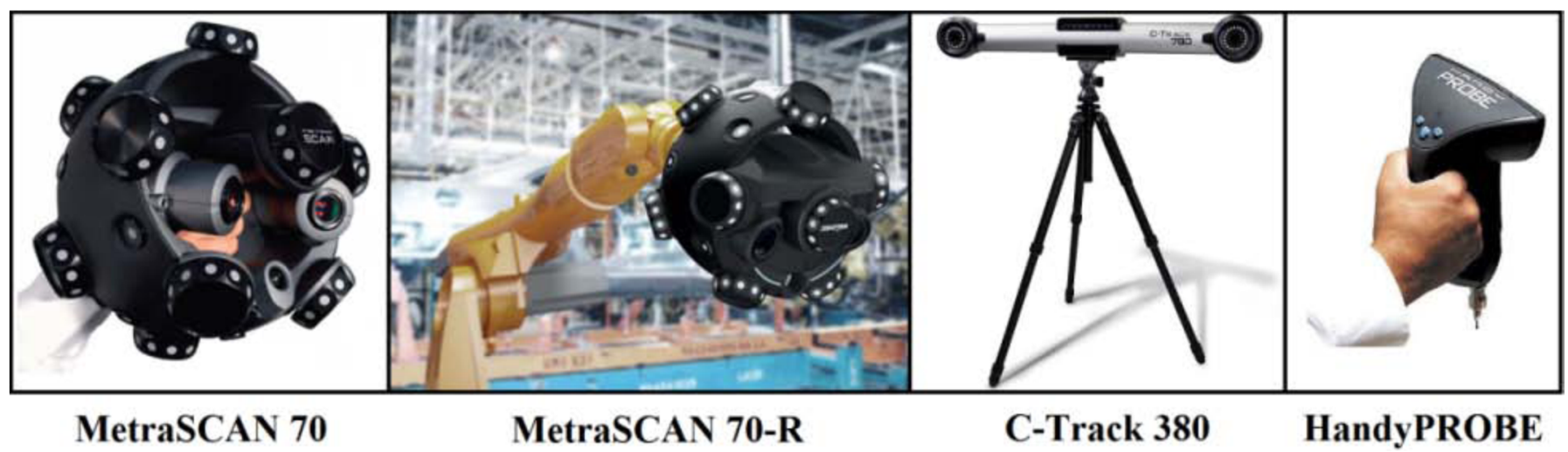

Figure 2. Alternatives from Creaform.

The HandyPROBE product is a wireless CMM (coordinate measuring machine) system consisting of a scanning probe with built-in reference points. These are continuously and dynamically scanned by the C-Track 380 optical system, from which points are then obtained for position evaluation. The basic parameters of three of the scanning devices listed above are displayed in Table 1.

Table 1. Technical specification of Creaform products.

\begin{tabular}{lccc}
\hline Parameter & MetraSCAN 70 & MetraSCAN 70R & HandyPROBE \\
\hline Price (EUR) & 67,350 & 130,000 & 38,500 \\
Weight (kg) & $1.85 \mathrm{~kg}$ & $1.85 \mathrm{~kg}$ & $0.45 \mathrm{~kg}$ \\
Dimensions (mm) & & $282 \times 250 \times 282$ & $159 \times 97$ \\
Measuring speed (pts/s) & 36,000 & 30 \\
Volumetric accuracy (mm) & 0.075 & 0.022 \\
Spacing distance (mm) & $50 / 2 \times 70$ & $\mathrm{~N} / \mathrm{A}$ \\
Depth/width FOV (Field of View) (mm) & $10-90 \%$ & $\mathrm{~N} / \mathrm{A}$ \\
Operating humidity range (\%) & $15-40$ & $10-90 \%$ \\
Working temperature $\left({ }^{\circ} \mathrm{C}\right)$ & & $15-40{ }^{\circ} \mathrm{C}$ \\
\hline
\end{tabular}

The following three laser scanners from Nikon can be combined with coordinate measuring systems: Nikon XC65Dx, Nikon LC60Dx and Nikon LC15Dx (Table 2). They are characterized by a relatively high accuracy, which is slightly affected by the accuracy of the CMM. The following additional hardware is required for the scanner application: the Renishaw PH10M (Q) motorized three-axis head and the optical probe driver, let us say, scanner. To generate movements of the measuring probe around the measured part, the Focus Scan software, which is an integral part of the Focus Inspection software, uses its CAD model. This software is also part of the investment package.

The accuracy of the Metronor DUO from the Norwegian company Metronor AS is comparable to that of the HandyPROBE product. The advantage of this wireless CMM system is its greater distance from the measured objects, allowing measurements to be performed on multiple workbenches without the need to move the optical scanning system. The product comes with PowerInspect software. The ATOS Triple Scan optical scanner uses a method of illuminating an object with structured light, specifically narrow-band blue light, which allows measurement independent of ambient light conditions. It uses two eight-megapixel cameras to detect changes in the shape of the raster, from which the shape and dimensions of the scanned part are then determined using factory software. Its slight disadvantage is the need to place reference points around the measured object. Basic technical information about the Metronor DUO and ATOS III Triple Scan devices can be found in Table 3. 
Table 2. Technical specification of Nikon products.

\begin{tabular}{lccc}
\hline Parameter & XC65Dx & LC60Dx & LC15Dx \\
\hline Price (EUR) & 97,130 & 65,110 & 64,850 \\
Weight (kg) & 0.44 & 0.39 & 0.37 \\
Dimensions (mm) & $155 \times 86 \times 142$ & $\mathrm{~N} / \mathrm{A}$ & $100 \times 104 \times 58$ \\
Measuring speed (pts/s) & 75,000 & 75,000 & 70,000 \\
Accuracy (mm) & 0.012 & 0.009 & 0.006 \\
Spacing distance (mm) & 75 & 95 & 60 \\
Depth/width FOV (mm) & $3 \times 65 / 3 \times 65$ & $60 /-$ & $15 /-$ \\
Operating humidity range $(\%)$ & $10-90 \%$ & $10-90 \%$ & $10-90 \%$ \\
Working temperature $\left({ }^{\circ} \mathrm{C}\right)$ & $10-40{ }^{\circ} \mathrm{C}$ & $10-40{ }^{\circ} \mathrm{C}$ & $10-40{ }^{\circ} \mathrm{C}$ \\
\hline
\end{tabular}

Table 3. Technical specification of products Metronor DUO and ATOS III Triple Scan.

\begin{tabular}{lll}
\hline Parameter & Metronor DUO & ATOS III Triple Scan \\
\hline Price (EUR) & 41,700 & 98,540 \\
Weight (kg) & 0.52 & 7.5 \\
Dimensions (mm) & $500 \times 200 \times 30$ & $155 \times 86 \times 142$ \\
Measuring speed (pts/s) & 35 & 75,000 \\
Accuracy (mm) & 0.025 & 0.01 \\
Spacing distance (mm) & $1500-15,000$ & $490-2000$ \\
Depth FOV (Field of View) (mm) & & 230 \\
Width FOV (Field of View) (mm) & $10-45^{\circ} \mathrm{C}$ & $250 \times 250$ \\
Working temperature $\left({ }^{\circ} \mathrm{C}\right)$ & $<90 \%$ & $5-40{ }^{\circ} \mathrm{C}$ \\
Operating humidity range $(\%)$ & & $10-90 \%$ \\
\hline
\end{tabular}

The system can be supplemented with a touch probe working on a similar principle to the HandyPROBE and Metronor DUO, i.e., on the optical scanning of fixed reference points located on its body. The investment includes the already-mentioned KUKA mechanical arm and GOM Inspect Professional system control and measurement evaluation software.

\subsection{Pairwise Comparison of Expert Evaluation Criteria}

On the basis of personal recollection and interviews with experts, data were obtained to select the following criteria:

- Degree of education $f_{1}$;

- Practical experience with RE systems $f_{2}$;

- Theoretical knowledge in the field of quality inspection $f_{3}$;

- Economic knowledge $f_{4}$.

Practical experience is necessary so that the expert can evaluate the technical specifications of a particular product from its manual. In addition, they should know something about quality inspection because not all of the machines compared are able to measure to the required degree of accuracy $[27,28]$. A study of the firm's finances should ensure that there are sufficient funds to purchase a device with all the necessary gadgets. Finally, a reasonable level of education expresses the ability to carry out an analysis from the available documents and information (Table 4) [29,30].

Table 4. Pairwise criteria comparison for evaluation of experts.

\begin{tabular}{ccccc}
\hline Criterion & $f_{1}$ & $f_{\mathbf{2}}$ & $f_{3}$ & $f_{\mathbf{4}}$ \\
\hline$f_{1}$ & 1 & $1 / 9$ & $1 / 8$ & $1 / 5$ \\
$f_{2}$ & 9 & 1 & 3 & 5 \\
$f_{3}$ & 8 & $1 / 3$ & 1 & 3 \\
$f_{4}$ & 5 & $1 / 5$ & $1 / 3$ & 1 \\
\hline
\end{tabular}


From the table above it is necessary to determine the characteristic polynomial by development of the following determinant:

$$
\operatorname{det}\left(A_{i}-\lambda \cdot J\right)=0
$$

where $A_{i}$ is the pairwise comparison matrix and $J$ is the identity matrix. Laplace's development of the determinant was used in the following calculation:

$$
\operatorname{det}|A|=\sum_{i=1}^{n}(-1)^{i+j} \cdot a_{i j} \cdot M_{i j}^{A}
$$

where $M_{i j}^{A}$ is the minor of a particular matrix $\left|S_{i j}^{A}\right|$.

From the calculated characteristic polynomial, we have identified the roots that are used to count the eigenvalue of the matrix [31], which are as follows:

$$
\begin{aligned}
\lambda_{1}= & 0.0186+0.28505 \mathrm{i} \\
\lambda_{2}= & 0.0186-0.28505 \mathrm{i} \\
& \lambda_{3}=4.1746 \\
& \lambda_{4}=0.1373
\end{aligned}
$$

The eigenvalue of the matrix is then calculated according to the following formula:

$$
\max \left|\lambda_{i}\right|=\lambda_{\max }=4.1746
$$

Consistency index $\lambda_{\max }$ represents the condition for the acceptance of a reciprocal pairwise comparison matrix.

By further modification the consistency criterion can be calculated as follows:

$$
\lambda_{\max }-n \leq \alpha\left(\bar{\lambda}_{\max }(n)-n\right)
$$

Using the estimator $\bar{\lambda}_{\max }$, i.e., applying the following approximation function:

$$
\lambda_{\max }(n)=1.7699 n-4.3513
$$

The equation can be modified and thus obtain the consistency of our matrix as follows:

$$
\begin{gathered}
\lambda_{\max } \leq n+\alpha(1.7699 n-4.3513) \\
4.1746 \leq 4+0.1(1.7699 \times 4-4.3513) \\
4.1746 \leq 4.2728
\end{gathered}
$$

The calculation shows that the condition is valid and the criteria for pairwise comparison matrix of expert assessment can be accepted. The procedure substitutes the standard Saaty approach to computing the consistency ratio $C I$. For illustration purposes we also present his method of calculation below:

$$
C R=C I / R I \leq 0.1 .
$$

where $C R$ is the consistency ratio, $C I$ is the consistency index, and $R I$ is a random index. Let us say the coefficient is selected from the tables, its value for the matrix size $n=4$ is 0.90 [32-37].

$$
\begin{gathered}
C I=\frac{\lambda_{\max }-n}{n-1}=\frac{4.1746-4}{4-1}=0.0582 \\
C R=\frac{0.0582}{0.90} \cong 0.0647 \leq 0.1
\end{gathered}
$$


In the next step, the eigenvector of the matrix was determined by substituting eigenvalues to the system of equations of the form $(A-\lambda \cdot J) x=0$, as follows :

$$
\left|\begin{array}{cccc}
3.1746 & 1 / 9 & 1 / 8 & 1 / 5 \\
9 & 3.1746 & 3 & 5 \\
8 & 1 / 3 & 3.1746 & 3 \\
5 & 1 / 5 & 1 / 3 & 3.1746
\end{array}\right| \cdot\left|\begin{array}{c}
x_{1} \\
x_{2} \\
x_{3} \\
x_{4}
\end{array}\right|=\begin{aligned}
& 0 \\
& 0 \\
& 0
\end{aligned}
$$

The listed system of equations is a homogeneous system of linear equations and can have both zero and nonzero solutions (if the value of the matrix is less than $n$, it can have many linearly dependent solutions). To solve this system of linear equations one of the variables must be equal to 1 . We have chosen $x_{1}$.

$$
\left|\begin{array}{ccc}
3.1746 & 3 & 5 \\
1 / 3 & 3.1746 & 3 \\
1 / 5 & 1 / 3 & 3.1746
\end{array}\right| \cdot\left|\begin{array}{c}
x_{2} \\
x_{3} \\
x_{4}
\end{array}\right|=\begin{aligned}
& -9 \\
& -8 \\
& -5
\end{aligned}
$$

The solution of that system is the eigenvector of this matrix $x_{1}=1 ; x_{2}=14.6955$; $x_{3}=7.1342 ; x_{4}=3.2499$. We can calculate its normalized version as follows:

$$
\begin{gathered}
v_{k n_{i}}=\frac{v_{k_{i}}}{\sum_{j=1}^{k} v_{k_{j}}} \\
v_{k}=\left|\begin{array}{c}
1 \\
14.6955 \\
7.1342 \\
3.2499
\end{array}\right| v_{k n}=\left|\begin{array}{l}
0.0383 \\
0.5635 \\
0.2736 \\
0.1246
\end{array}\right| \\
\sum v_{k_{j}}=26.0796 \sum v_{k n_{j}}=1
\end{gathered}
$$

\subsection{Pairwise Comparison of Experts According to Individual Criteria}

The table below shows information about the pairwise comparison of experts according to selected individual criteria, based on the education of each expert.

Quality manager $\left(a_{1}\right)$ and economist $\left(a_{3}\right)$ have a university degree. Technician $\left(a_{2}\right)$ has secondary technical education. The individual comparisons are listed in Table 5.

Table 5. Expert comparison by selected criteria.

\begin{tabular}{cccccccccccccccccc}
\hline Kr. & \multicolumn{1}{c}{$f_{\mathbf{1}}$} & \multicolumn{1}{c}{$f_{\mathbf{2}}$} & \multicolumn{1}{c}{$f_{\mathbf{3}}$} & \multicolumn{3}{c}{$f_{\mathbf{4}}$} \\
\hline & $\boldsymbol{a}_{\mathbf{1}}$ & $\boldsymbol{a}_{\mathbf{2}}$ & $\boldsymbol{a}_{\mathbf{3}}$ & $\boldsymbol{a}_{\mathbf{4}}$ & $\boldsymbol{a}_{\mathbf{1}}$ & $\boldsymbol{a}_{\mathbf{2}}$ & $\boldsymbol{a}_{\mathbf{3}}$ & $\boldsymbol{a}_{\mathbf{4}}$ & $\boldsymbol{a}_{\mathbf{1}}$ & $\boldsymbol{a}_{\mathbf{2}}$ & $\boldsymbol{a}_{\mathbf{3}}$ & $\boldsymbol{a}_{\mathbf{4}}$ & $\boldsymbol{a}_{\mathbf{1}}$ & $\boldsymbol{a}_{\mathbf{2}}$ & $\boldsymbol{a}_{\mathbf{3}}$ & $\boldsymbol{a}_{\mathbf{4}}$ \\
\hline$a_{1}$ & 1 & 3 & 1 & 3 & 1 & 2 & 9 & 6 & 1 & 3 & 9 & 5 & 1 & 2 & $1 / 7$ & 3 \\
$a_{2}$ & $1 / 3$ & 1 & $1 / 4$ & $1 / 3$ & $1 / 2$ & 1 & 9 & 6 & $1 / 3$ & 1 & 9 & 4 & $1 / 2$ & 1 & $1 / 8$ & 2 \\
$a_{3}$ & 1 & 4 & 1 & 4 & $1 / 9$ & $1 / 9$ & 1 & $1 / 4$ & $1 / 9$ & $1 / 9$ & 1 & $1 / 5$ & 7 & 8 & 1 & 8 & $1 / 3$ \\
$a_{4}$ & $1 / 3$ & 3 & $1 / 4$ & 1 & $1 / 6$ & $1 / 6$ & 4 & 1 & $1 / 5$ & $1 / 4$ & 5 & 1 & $1 / 3$ & $1 / 2$ & $1 / 8$ & 1 \\
\hline
\end{tabular}

In the same way as in the case of the pairwise comparison of these criteria, we calculated all the necessary parameters for individual comparisons of variants according to the respective criteria from the matrices of pairwise comparisons mentioned above. The characteristic polynomials are as follows: 


$$
\begin{aligned}
& \left|A_{f 1}\right|=\left|\begin{array}{cccc}
1-\lambda & 3 & 1 & 3 \\
1 / 3 & 1-\lambda & 1 / 4 & 1 / 3 \\
1 & 4 & 1-\lambda & 4 \\
1 / 3 & 3 & 4 & 1-\lambda
\end{array}\right| \Delta\left(\lambda_{A f 1}\right)=\lambda^{4}-4 \lambda^{3}-\frac{17 \lambda}{6}-\frac{1}{9} \\
& \left|A_{f 2}\right|=\left|\begin{array}{cccc}
1 / 3 & 3 & 4 & 1-\lambda \\
1-\lambda & 2 & 9 & 6 \\
1 / 2 & 1-\lambda & 9 & 6 \\
1 / 9 & 1 / 9 & 1-\lambda & 1 / 4 \\
1 / 6 & 1 / 6 & 4 & 1-\lambda
\end{array}\right| \Delta\left(\lambda_{A f 2}\right)=\lambda^{4}-4 \lambda^{3}-\frac{37 \lambda}{12}-\frac{25}{48} \\
& \left|A_{f 3}\right|=\left|\begin{array}{cccc}
1-\lambda & 3 & 9 & 5 \\
1 / 3 & 1-\lambda & 9 & 4 \\
1 / 9 & 1 / 9 & 1-\lambda & 1 / 5 \\
1 / 5 & 1 / 4 & 5 & 1-\lambda
\end{array}\right| \quad \Delta\left(\lambda_{A f 4}\right)=\lambda^{4}-4 \lambda^{3}-\frac{99 \lambda}{25}-\frac{616}{675} \\
& \left|A_{f 4}\right|=\left|\begin{array}{cccc}
1-\lambda & 2 & 1 / 7 & 3 \\
1 / 2 & 1-\lambda & 1 / 8 & 2 \\
7 & 8 & 1-\lambda & 8 \\
1 / 3 & 1 / 2 & 1 / 8 & 1-\lambda
\end{array}\right| \Delta\left(\lambda_{A f 4}\right)=\lambda^{4}-4 \lambda^{3}-\frac{107 \lambda}{56}-\frac{13}{112}
\end{aligned}
$$

From the characteristic polynomial $\Delta\left(\lambda_{A f i}\right)$ of individual matrices $A_{f i}$ we calculated their roots. According to Equation (4) we determined the parameters of lambda, and according to Equation (6) we assessed the consistency of the matrices, as follows:

$$
\begin{gathered}
A_{f 1}=\left|\begin{array}{c}
\lambda_{3}=4.1649 \\
\lambda_{1}=-0.0629+0.8233 i \\
\lambda_{2}=-0.0629-0.8233 i \\
\lambda_{4}=-0.0391 \\
\lambda_{3}=4.1833 \\
\lambda_{1}=-0.0101+0.8233 i \\
\lambda_{2}=-0.0101-0.8233 i \\
\lambda_{4}=-0.1631 \\
\lambda_{3}=4.2330 \\
A_{f 2}
\end{array}\right| \quad \Rightarrow \lambda_{\max }=4.1649 \Rightarrow 4.1649 \leq 4.2728 \\
A_{f 3}=-0.0069+0.9916 i \\
\lambda_{2}=-0.0069-0.9916 i \\
\lambda_{4}=-0.2192 \\
\lambda_{3}=4.1145 \\
\lambda_{14}=-0.0271+0.6835 i \\
\lambda_{2}=-0.0271-0.6835 i \\
\lambda_{4}=-0.0603
\end{gathered} \mid \quad \Rightarrow \lambda_{\max }=4.233 \Rightarrow 4.233 \leq 4.2728
$$

The consistency condition is met in the case of all the comparisons, so we can accept the matrices. The eigenvalues of the matrices and the eigenvalues of vectors of the matrices are as follows: 


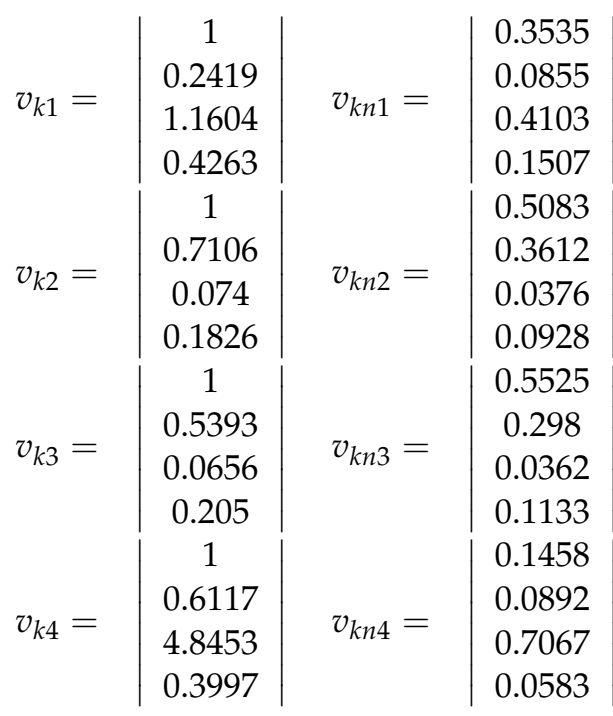

The table below provides an overview of the importance of individual experts involved in the investment selection. The values of the scalar product of the weight vector and the specific vectors representing the experts are displayed in the weighted sum line. As can be observed, the decisions of the quality manager will have the greatest weight at this level of the hierarchical structure. He is followed by his technician, economist, and engineer $[38,39]$.

\section{Results}

Based on the information available, all the experts have been compared against each other according to particular criteria. In this way, the weight of each expert has been calculated. The results are recorded in the table below (Table 6). These values will subsequently be used in the product selection process.

Table 6. Weights of particular experts.

\begin{tabular}{|c|c|c|c|c|c|}
\hline Criterion & Weight & Quality Manager & Technician & Economist & Engineer \\
\hline Education degree & 0.0383 & 0.3535 & 0.0855 & 0.4103 & 0.1507 \\
\hline Practical experiences with RE systems & 0.5635 & 0.5083 & 0.3612 & 0.0376 & 0.0928 \\
\hline Theoretical knowledge from quality inspection & 0.2736 & 0.5525 & 0.298 & 0.0362 & 0.1133 \\
\hline Economic knowledge & 0.1246 & 0.1458 & 0.0892 & 0.7067 & 0.0583 \\
\hline Weighted sum & & 0.4693 & 0.2995 & 0.1349 & 0.0963 \\
\hline
\end{tabular}

In the same way, the weight of each selected criterion of the scanners has been calculated. Pairwise comparison by members of the evaluation team at this level of hierarchy structure should reflect their personal preferences, according to which they will give priority to a specific product. The results are shown in the following table (Table 7).

Table 7. Weight of product assessment criteria.

\begin{tabular}{lcccccccc}
\hline Expert & Weight & $f_{\mathbf{1}}$ & $f_{\mathbf{2}}$ & $f_{\mathbf{3}}$ & $f_{\mathbf{4}}$ & $f_{5}$ & $f_{\mathbf{6}}$ & $f_{7}$ \\
\hline Quality manager & 0.4693 & 0.0228 & 0.4286 & 0.1083 & 0.1293 & 0.1582 & 0.1170 & 0.0358 \\
Technician & 0.2995 & 0.0232 & 0.4391 & 0.1958 & 0.0718 & 0.0597 & 0.1299 & 0.0805 \\
Economist & 0.1349 & 0.3375 & 0.2646 & 0.0352 & 0.0667 & 0.0887 & 0.1499 & 0.0574 \\
Engineer & 0.0963 & 0.0245 & 0.4574 & 0.1734 & 0.0943 & 0.0806 & 0.1170 & 0.0528 \\
Weighted sum: & & 0.0655 & 0.4124 & 0.1309 & 0.1003 & 0.1118 & 0.1253 & 0.0537 \\
\hline
\end{tabular}

The last step in the analysis is to process the matrices of pairwise comparisons, in which every product is assessed according to each criterion for product assessment 
(Table 8). The considered variants are as follows: MetraSCAN $70\left(a_{1}\right)$, MetraSCAN 70-R $\left(a_{2}\right)$, HandyPROBE $\left(a_{3}\right)$, Nikon XC65Dx $\left(a_{4}\right)$, Nikon LC60Dx $\left(a_{5}\right)$, Nikon LC15Dx $\left(a_{6}\right)$, Metronor DUO $\left(a_{7}\right)$, and ATOS Triple Scan $\left(a_{8}\right)$.

Table 8. Final product order.

\begin{tabular}{lccccccccc}
\hline Criterion & Weight & $\boldsymbol{a}_{\mathbf{1}}$ & $\boldsymbol{a}_{\mathbf{2}}$ & $\boldsymbol{a}_{\mathbf{3}}$ & $\boldsymbol{a}_{\mathbf{4}}$ & $\boldsymbol{a}_{\mathbf{5}}$ & $\boldsymbol{a}_{\mathbf{6}}$ & $\boldsymbol{a}_{\mathbf{7}}$ & $\boldsymbol{a}_{\mathbf{8}}$ \\
\hline Price $\left(f_{1}\right)$ & 0.0655 & 0.0894 & 0.0204 & 0.2930 & 0.0497 & 0.1252 & 0.1252 & 0.2473 & 0.0497 \\
Accuracy $\left(f_{2}\right)$ & 0.4124 & 0.0266 & 0.0198 & 0.0526 & 0.1292 & 0.2216 & 0.3488 & 0.0640 & 0.1375 \\
Portability $\left(f_{3}\right)$ & 0.1309 & 0.2288 & 0.0326 & 0.3073 & 0.0310 & 0.0310 & 0.0310 & 0.3073 & 0.0310 \\
Sensed area $\left(f_{4}\right)$ & 0.1003 & 0.1163 & 0.1163 & 0.0156 & 0.2009 & 0.0910 & 0.0584 & 0.0157 & 0.3859 \\
Depth of field $\left(f_{5}\right)$ & 0.1118 & 0.0339 & 0.0339 & 0.2928 & 0.0516 & 0.0699 & 0.0204 & 0.2784 & 0.2190 \\
Sensing rate $\left(f_{6}\right)$ & 0.1253 & 0.1305 & 0.1174 & 0.0175 & 0.1714 & 0.0800 & 0.0567 & 0.0165 & 0.4100 \\
Possibility to move with & & & & & & & & \\
sensed object \& ease of & 0.0537 & 0.2082 & 0.2082 & 0.2082 & 0.0334 & 0.0334 & 0.0334 & 0.2416 & 0.0334 \\
implement. $\left(f_{7}\right)$ & & & & & & & & \\
Weighted sum: & & 0.0898 & 0.0551 & 0.1288 & 0.1098 & 0.1324 & 0.1731 & 0.1306 & 0.1804 \\
Order: & & 7 & 8 & 5 & 6 & 3 & 2 & 4 & 1 \\
\hline
\end{tabular}

As can be observed in the table above, the ATOS Triple Scan corresponds best to all the stated criteria, and slightly worse is the Nikon LC15Dx. In this case, the best solution is not the cheapest, for these two machines are more expensive than the others. Using this method, and by engaging staff in the process, a company can prevent many mistakes before buying and implementing any equipment under consideration. Before choosing one of the solutions, the firm can perform an additional analysis of the profitability of an investment, so that they can select the best option.

\section{Discussion}

The figure below (Figure 3) shows the whole four-level hierarchical structure, in which the calculated weights of the evaluation team, the criteria for the equipment, and, finally, on the fourth level, the weight determining the final order of alternatives can be observed.

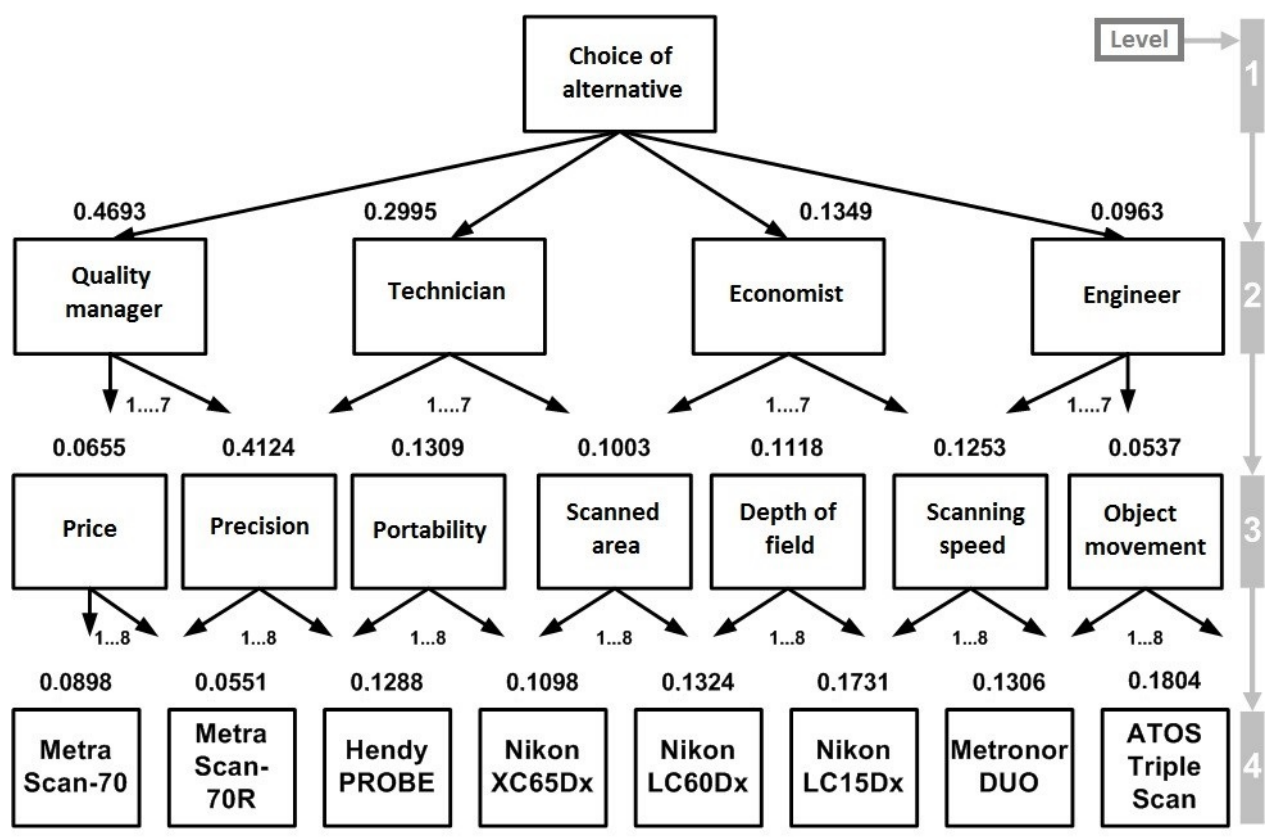

Figure 3. Diagram of multilevel hierarchical structure with values of individual weights. 
Due to the fact that the AHP method requires relatively demanding mathematical calculations, and the matrices themselves are larger, a function (see Algorithm 1) in the MATLAB program was used to perform the calculations. The function itself verifies the inverse axiom; let us say that the reciprocity rule $\mathrm{r} j i=1 / \mathrm{r} i j$, which, if not met, will print an error message. In the next step, it checks the consistency of the matrix (if it is not consistent, it returns an error message), and, finally, it calculates the required vectors.

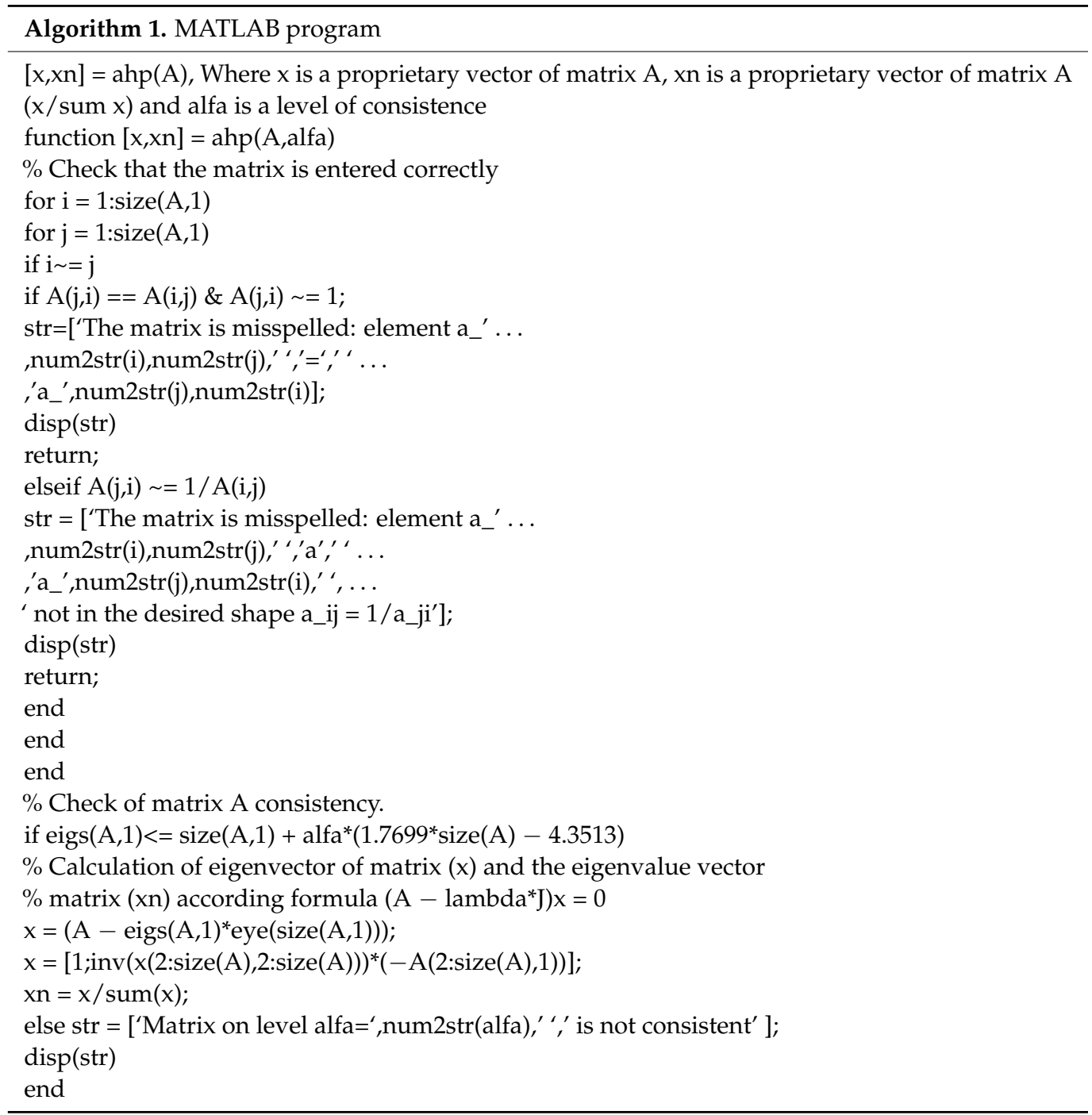

\section{Conclusions}

The presented information shows the way in which it is possible to proceed with the selection of a scanning device for reverse engineering for a company. The overall methodology is presented, from the selection of important criteria, through their evaluation, to the selection of the most appropriate technical solution. It is a complex, but demanding, methodology that can objectify selection. The article presents the whole procedure applied to a specific example, with the weight of individual criteria. A very effective AHP pairwise comparison methodology is used. The paper presents a novel application of the AHP method, using, as an example, the selection of a reverse engineering scanning device, and introduces a new perspective in this field. Among the many benefits it brings are enhanced effectiveness and cost saving. This evaluation process was performed in the company under real conditions and verified in real terms.

Author Contributions: Conceptualization, J.B. and M.M.; methodology, J.B.; software, P.K.; validation, L'.̌̌. and J.B.; formal analysis, J.B.; investigation, J.B.; resources, J.B. and P.K.; data curation, J.B.; 
writing-original draft preparation, J.B. and M.M.; writing - review and editing, J.B.; visualization, J.B.; supervision, J.B. and P.K.; project administration, J.B.; funding acquisition, J.B. All authors have read and agreed to the published version of the manuscript.

Funding: The paper is a part of the research conducted within the project APVV-18-0527 “Development and optimization of additive manufacturing technology and design of device for production of components with optimized strength and production costs" funded by the Slovak Research and Development Agency. This paper was completed in association with the project "Innovative and additive manufacturing technology-new technological solutions for 3D printing of metals and composite materials", reg. no. CZ.02.1.01/0.0/0.0/17_049/0008407 financed by Structural Funds of the European Union and project. The paper is a part of the research conducted within the project VEGA 1/0665/21 "Research and optimization of technological parameters of progressive additive manufacturing of effective protective equipment against COVID-19" funded by the Ministry of Education of Slovak Republic and to the Slovak Academy of Sciences.

Institutional Review Board Statement: Not applicable.

Informed Consent Statement: Not applicable.

Data Availability Statement: The data are available at Slovak University of Technology in Bratislava.

Conflicts of Interest: The authors declare no conflict of interest.

\section{References}

1. Dúbravčík, M.; Kender, S. Application of Reverse Engineering Techniques in Mechanics System Services. Procedia Eng. 2012, 48, 96-104. [CrossRef]

2. Buonamici, F.; Carfagni, M.; Furferi, R.; Governi, L.; Lapini, A.; Volpe, Y. Reverse engineering of mechanical parts: A templatebased approach. J. Comput. Des. Eng. 2017, 5, 145-159. [CrossRef]

3. Moon, S.; Ko, K. A point projection approach for improving the accuracy of the multilevel B-spline approximation. J. Comput. Des. Eng. 2017, 5, 173-179. [CrossRef]

4. Rysiński, J.; Wrobel, I. Diagnostics of machine parts by means of reverse engineering procedures. Adv. Mech. Eng. 2015, 7, 1687814015584543. [CrossRef]

5. Docchio, F.; Sansoni, G.; Trebeschi, M. Inspection, 3D modelling, and rapid prototyping of cultural heritage by means of a 3D optical digitiser. Opt. Methods Arts Archaeol. 2005, 5857, 58570D. [CrossRef]

6. Pandilov, Z.; Betim, S.; Dejan, S. Reverse engineering an effective tool for design and development of mechanical parts. Acta Tech. Corviniensis-Bull. Eng. 2018, 11, 113-118.

7. Atanasova-Pacemska, T.P.; Lapevski, M.; Timovski, R. Analytical hierarchical process (ahp) method application in the process of selection and evaluation. In Proceedings of the UNITECH-International Scientific Conference, Gabrovo, Bulgaria, 21-22 November 2014; Volume 14.

8. Buonamici, F.; Carfagni, M.; Furferi, R.; Governi, L.; Lapini, A.; Volpe, Y. Reverse engineering modeling methods and tools: A survey. Comput. Des. Appl. 2017, 15, 443-464. [CrossRef]

9. $\quad$ Eldad, E. Reversing: Secrets of Reverse Engineering; Wiley Publishing, Inc.: Indianapolis, ID, USA, 2015; ISBN 0-7645-7481-7.

10. Thompson, W.; Owen, J.; Germain, H.D.S.; Stark, S.; Henderson, T. Feature-based reverse engineering of mechanical parts. IEEE Trans. Robot. Autom. 1999, 15, 57-66. [CrossRef]

11. Kumar, A.; Jain, P.; Pathak, P. Conception of Part Reconstruction: Integration of Non-Contact Scanning and Rapid Prototyping. In Proceedings of the Conference AM-2014, Bengaluru, India, 1-2 September 2014.

12. Prochazkova, J.; Procházka, D.; Landa, J. Sharp Feature Detection as a Useful Tool in Smart Manufacturing. ISPRS Int. J. Geo-Inf. 2020, 9, 422. [CrossRef]

13. Miądlicki, K.; Jasiewicz, M.; Gołaszewski, M.; Królikowski, M.; Powałka, B. Remanufacturing System with Chatter Suppression for CNC Turning. Sensors 2020, 20, 5070. [CrossRef]

14. Raut, L.; Barai, G.; Shete, S. Design and development of a component by reverse engineering. Int. J. Res. Eng.Technol. 2015, 4, 539-546.

15. Ivana, R.; Zuzana, M. The Analysis of AHP method and its potential use in logistics. Acta Montanistica Slovaca 2009, 14, 103-112.

16. Gospodarek, M.; Rybarczyk, P.; Szulczyński, B.; Gebicki, J. Comparative Evaluation of Selected Biological Methods for the Removal of Hydrophilic and Hydrophobic Odorous VOCs from Air. Processes 2019, 7, 187. [CrossRef]

17. Ruiz-Ramos, J.; Marino, A.; Boardman, C.; Suarez, J. Continuous Forest Monitoring Using Cumulative Sums of Sentinel-1 Timeseries. Remote Sens. 2020, 12, 3061. [CrossRef]

18. Koczkodaj, W.W.; Szybowski, J.; Wajch, E. Inconsistency indicator maps on groups for pairwise comparisons. Int. J. Approx. Reason. 2016, 69, 81-90. [CrossRef]

19. Leal, J.E. AHP-express: A simplified version of the analytical hierarchy process method. MethodsX 2019, 7, 100748. [CrossRef] [PubMed] 
20. Freerk, A.L. Multi-Criteria Decision Analysis via Ratio and Difference Judgement; Applied Optimization; Springer: Boston, MA, USA, 1999. [CrossRef]

21. Viana, V.R.; Ipma-B, P. Using the Analytic Hierarchy Process (AHP) to Select and Prioritize Projects in a Portfolio; PMI Global Congress: Washington, DC, USA, 2010; pp. 1-12.

22. Podvezko, V.; Mitkus, S.; Trinkūniene, E. Complex evaluation of contracts for construction. J. Civ. Eng. Manag. 2010, 16, 287-297. [CrossRef]

23. Kim, S.; Kim, B. A Decision-Making Model for Adopting Al-Generated News Articles: Preliminary Results. Sustainability 2020, 12, 7418. [CrossRef]

24. Kristbaum, J.P.; Ciarallo, F.W. Strategic Decision Facilitation: Supporting Critical Assumptions of the Human in Empirical Modeling of Pairwise Value Comparisons. Systems 2020, 8, 30. [CrossRef]

25. Derrek, P.H.; Neda, J.; Sarah, E.; Medland, P.M. Thompson, Chapter Nine-Continuous Inflation Analysis: A Threshold-Free Method to Estimate Genetic Overlap and Boost Power in Imaging Genetics; Adrian, V., Dalca, N., Batmanghelich, K., Li, S., Mert, R.S., Eds.; Imaging Genetics; Academic Press: Cambridge, MA, USA, 2018; pp. 147-162, ISBN 9780128139684. [CrossRef]

26. Nordstokke, D.; Stelnicki, A.M. Pairwise Comparisons. In Encyclopedia of Quality of Life and Well Being Research; Michalos, A.C., Ed.; Springer: Dordrecht, The Netherlands, 2014. [CrossRef]

27. Sébastien, R.; Laroche, F. Durupt Alexandre, Bernard Alain, Knowledge Based Reverse Engineering Methodology. In Proceedings of the ASME 2012 11th Biennial Conference on Engineering Systems Design and Analysis, ESDA 2012, Nantes, France, 2-4 July 2012. [CrossRef]

28. Alexander, M. Manažérstvo Kvality: História, Koncepty, Metódy, 1st ed.; Epos: 2006; p. 752, ISBN 80-8057-656-4. Available online: https:// books.google.com.hk/books/about/Mana\%C5\%BE\%C3\%A9rstvo_kvality.html?id=85u2AAAACAAJ\&redir_ esc $=\mathrm{y}$ (accessed on 14 December 2021).

29. Creath, K.; Wyant, J.C. Moiré and Fringe Projection Techniques. In Optical Shop Testing, 2nd ed.; Malacara, D., Ed.; John Wiley \& Sons, Inc.: Hoboken, NJ, USA, 1992; pp. 653-685.

30. Zalai, K.; Kalafutová, E.; Šnircová, J. Financial and Economic Analysis of the Company; Sprint: Bratislava, Slovensko, 2002; p. 305, ISBN 80-88848-94-6.

31. Várady, T.; Martin, R.R.; Cox, J. Reverse engineering of geometric models-An introduction. Comput. Des. 1997, 29, 255-268. [CrossRef]

32. Svetlík, J.; Demeč, P. Methods of Identifying the Workspace of Modular Serial Kinematic Structures. Appl. Mech. Mater. 2013, 309, 75-79. [CrossRef]

33. Alonso, J.A. Lamata Teresa, Consistency in the analytic hierarchy process: A new approach. Int. J. Uncertain. Fuzziness Knowl.-Based Syst. 2006, 14, 445-459. Available online: http:/ / hera.ugr.es/doi/16515833.pdf (accessed on 10 November 2021).

34. Raja, V.; Fernandes, K.J. Fernandes, Reverse Engineering-An Industrial Perspective; Springer: London, UK, 2008; ISBN 978-1-84628855-5. [CrossRef]

35. Park, J.; DeSouza, G.N. 3-D Modeling of Real-World Objects Using Range and Intensity Images. In Machine Learning and Robot Perception; Springer: Berlin/Heidelberg, Germany, 2005; pp. 203-264. [CrossRef]

36. Rocchini, C.; Cignoni, P.; Montani, C.; Pingi, P.; Scopigno, R. A low cost 3D scanner based on structured light. Comput. Graph. Forum 2001, 20, 299-308. [CrossRef]

37. Boehler, W.; Marbs, A. The potential of non-contact close range laser scanners for cultural heritage recording. Int. Arch. Photogramm. Remote Sens. Spat. Inf.Sci. 2002, 34, 430-436.

38. Beniak, J.; Križan, P.; Matus, M.; Svatek, M. Ecological PLA plastic used for FDM rapid prototyping technology. In Proceedings of the International Multidisciplinary Scientific GeoConference Surveying Geology and Mining Ecology Management, SGEM, Albena, Bulgaria, 18-24 June 2015; Volume 1, pp. 117-123. [CrossRef]

39. Svetlik, J.; Demeč, P. Methods of Identifying the Workspace of Modular Serial Kinematic Structures. In Proceedings of the Applied Mechanics and Materials: CECOL 2012: 3rd Central European Conference on Logistics, Trnava, Slovakia, 28-30 November 2012; Volume 309, pp. 75-79, ISBN 978-303785636-9. 